\title{
PEMBINAAN ARSIP UNIT KERJA SEBAGAI UPAYA PENYELAMATAN ARSIP
}

\author{
Kurniatun \\ Arsip Universitas Gadjah Mada \\ kurniatun@ugm.ac.id
}

\begin{abstract}
Archives are a source of organizational memory, so that archives can be useful and must be managed properly. In connection with this matter, the author research while carrying out the task of Records Center. The method used in this research is action research.. If the provincial and district or city governments have a "Program Arsip Masuk Desa". University Archive of Universitas Gadjah Mada has a Records Center Development Program. This activity aims to foster records center within UGM so that archival governance can run well from the creating agency. The constraints faced in this activity are due to various factors of human resources, infrastructure and filing systems.
\end{abstract}

Keywords: archives, archive development, archival assistance, archive rescue and records center.

\section{Intisari}

Arsip merupakan sumber ingatan organisasi, agar arsip dapat berdaya guna harus dikelola dengan benar. Berkaitan dengan hal itu, penulis melakukan penelitian pada saat melaksanakan tugas Pendampingan Arsip Unit Kerja. Metode yang digunakan dalam penelitian ini adalah action research atau sering juga dikenal sebagai penelitian tindakan.Jika pemerintah provinsi dan kabupaten / kota mempunyai Program Arsip Desa (AMD), Arsip Universitas Gadjah Mada memiliki Program Pembinaan Arsip Unit Kerja. Kegiatan ini bertujuan untuk membina unit kerja di lingkungan UGM agar tata kelola kearsipan dapat berjalan dengan baik sejak dari unit pencipta arsip. Kendala yang dihadapi dalam kegiatan ini adalah karena faktor sumber daya manusia, sarana prasarana dan sistem kearsipan yang beragam.

Kata kunci: arsip, pembinaan arsip, pendampingan arsip, penyelamatan arsip dan unit kerja. 


\section{PENDAHULUAN}

Dalam bidang usaha dikenal istilah pendampingan usaha mikro, kecil dan menengah oleh perusahaan BUMN, begitu juga dalam bidang kearsipan. Untuk tingkat nasional dikenal lembaga yang bernama Arsip Nasional Republik Indonesia (ANRI). Salah satu tugas ANRI adalah melaksanakan Penyelenggaraan pembinaan kearsipan nasional (Sumber: http://www.anri.go.id). Begitu pula dengan Arsip Universitas Gadjah Mada (UGM) sebagai lembaga kearsipan perguruan tinggi, mempunyai tugas antara lain melaksanakan pengelolaan arsip statis (Archives Management), pengelolaan arsip dinamis inaktif dan pengembangan Records Center, serta pengembangan teknologi informasi kearsipan (sumber: http:// arsip.ugm.ac.id/). Berdasarkan tugas tersebut dapat diketahui bahwa Arsip UGM mempunyai kewajiban untuk melakukan pendampingan terhadap unit kerja dalam mengelola arsip dan pembentukan records center.

Saat ini lembaga/instansi pemerintah dituntut dapat menyajikan informasi secara terbuka kepada masyarakat. Keterbukaan informasi publik mempunyai makna yang luas karena semua lembaga pemerintah mempertanggungjawabkannya kepada masyarakat. Hal ini sesuai dengan Undang-Undang Dasar (UUD) 1945 dan Undang-Undang (UU) Nomor 14 Tahun 2008 tentang Keterbukaan Informasi Publik. UUD 1945 pasal 28F menyebutkan bahwa setiap orang berhak untuk berkomunikasi dan memperoleh informasi untuk mengembangkan pribadi dan lingkungan sosialnya, serta berhak untuk mencari, memperoleh, memiliki dan menyimpan informasi dengan menggunakan segala jenis saluran yang tersedia. Adapun yang dimaksud dengan informasi menurut UU Nomor 58 Tahun 2008 adalah keterangan, pernyataan, gagasan dan tanda-tanda yang mengandung nilai, makna dan pesan, baik data, fakta maupun penjelasannya yang dapat dilihat, didengar dan dibaca yang disajikan dalam berbagai kemasan dan format sesuai dengan perkembangan teknologi informasi dan komunikasi secara elektronik ataupun non elektronik. Sedangkan Informasi publik adalah informasi yang dihasilkan, disimpan, dikelola, dikirim dan/ atau diterima oleh suatu badan publik yang berkaitan dengan penyelenggara dan penyelenggaraan negara dan/atau penyelenggaraan badan publik lainnya yang sesuai dengan UU ini serta informasi lain yang berkaitan dengan kepentingan publik.

Salah satu bentuk penyajian informasi publik adalah dengan penyajian arsip. Oleh karena pentingnya keberadaan arsip, Mantan Kepala Arsip Nasional Djoko Utomo mengemukakan:

Dalam penyelenggaraan
pemerintahan yang amanah, peran
arsip sangat sentral. Sebab, arsip itu
merupakan tulang punggung
manajemen termasuk
penyelenggaraan pemerintahan
yang amanah. Tidak ada satu
kegiatan pun yang tidak
memerlukan arsip dan yang tidak
menghasilkan arsip (sumber: http://
www.suaramerdeka. com).

Berdasarkan pernyataan Djoko Utomo tersebut dapat diketahui betapa pentingnya arsip bagi penyelenggaraan pemerintahan dan layanan informasi kepada masyarakat. Oleh karena itu, pemerintah dituntut dapat menyelenggarakan kearsipan sesuai dengan ketentuan perundangan yang berlaku. Apabila diamati perhatian pemerintah terhadap arti penting arsip juga semakin meningkat. Hal ini dapat dilihat dari gebrakan pemerintah melalui Arsip Nasional Republik Indonesia (ANRI) dengan mencanangkan program "Arsip Masuk Desa (AMD) pada tahun 2009 dan Gerakan Nasional Sadar Tertib 
Arsip (GNSTA) pada tahun 2017".

Pencanangan AMD dilakukan oleh Presiden Susilo Bambang Yudhoyono di Gedung ANRI Jakarta, pada tanggal 31 Agustus 2009. Program AMD merupakan sistem informasi pengelolaan arsip pedesaan yang merupakan struktur pemerintahan paling bawah. Program AMD merupakan babak baru penertiban pengelolaan arsip pemerintahan di tingkat pedesaan, seperti pertanahan, kelahiran dan data kependudukan. Sedangkan pencanangan GNSTA dilaksanakan pada 22 Mar 2017 oleh Sekretaris Jenderal Kementerian Hukum dan Hak Azazi Manusia (KumHAM) RI, dengan disaksikan oleh Menteri KumHAM, Menteri Pendayagunaan Aparatur Negara dan Reformasi Birokrasi (PANRB), Kepala ANRI \& Kepala Badan Kepegawaian Negara (BKN) (sumber: https://twitter.com/arsipnasionalri).

Kalau pemerintah provinsi dan pemerintah kabupaten/ kota mempunyai program AMD, Arsip Universitas Gadjah Mada (UGM) juga mempunyai kegiatan serupa untuk meningkatkan pengelolaan arsip di lingkungan UGM. Arsip UGM merupakan lembaga kearsipan di lingkungan UGM. UU No. 43 Tahun 2009, pasal 1 ayat 17 menyebutkan arsip perguruan tinggi adalah lembaga kearsipan berbentuk satuan organisasi perguruan tinggi, baik negeri maupun swasta yang melaksanakan fungsi dan tugas penyelenggaraan kearsipan di lingkungan perguruan tinggi.

Arsip UGM telah melakukan kegiatan pendampingan kearsipan ke records center unit kerja di lingkungan UGM. Kegiatan ini sudah dilaksanakan sejak tahun 2010 dan sampai sekarang masih berjalan. Kegiatan ini dilakukan oleh beberapa arsiparis Arsip UGM dibawah koordinator Kepala Bidang Database yang bertanggung jawab kepada Kepala Arsip UGM.

\section{METODOLOGI}

Metode yang digunakan dalam penelitian ini adalah action research atau sering juga dikenal sebagai penelitian tindakan. Menurut V. Wiratna Sujarwadi ( 2014: 10) yang dimaksud dengan penelitian tindakan merupakan penelitian yang ditujukan untuk menemukan metode yang paling efektif dalam kegiatan sehari-hari dalam suatu instansi, organisasi maupun perusahaan. Oleh karena itu, dalam metode ini peneliti harus dapat menyeimbangkan antara teori dan praktik. Dalam melaksanakan metode ini, diawali dengan melakukan:

a. identifikasi permasalahan pengelolaan arsip pada saat awal kegiatan pembinaan arsip unit kerja dilakukan, yaitu dengan kegiatan survei arsip;

b. perencanaan pembinaan arsip yaitu biasanya dengan membuat proposal kegiatan pendampingan arsip;

c. tindakan pembinaan arsip kerja yaitu dengan memberikan sosialisasi akan arti penting arsip bagi unit kerja dan terjun langsung dalam pendampingan arsip di unit kerja;

d. evaluasi dengan melihat dampak yang ditimbulkan dari kegiatan dan analisis SWOT antara sebelum kegiatan pembinaan arsip unit kerja dilaksanakan dan pasca kegiatan; dan

e. kegiatan penyusunan laporan hasil kegiatan pembinaan arsip unit kerja dengan cara mempublikasikannya dalam bentuk makalah/karya ilmiah yang diterbitkan, misalnya melalui tulisan seperti ini. Hal ini bisa menjadi salah satu cara pembelajaran.

\section{KERANGKA PEMIKIRAN}

Sebelum membahas kegiatan pembinaan arsip unit kerja di lingkungan 
Universitas Gadjah Mada perlu kiranya diketahui pengertian arsip dan arsiparis berdasarkan Undang-Undang No. 43 Tahun 2009. Pasal 1 Undang-Undang No. 43 Tahun 2009 disebutkan pengertian:

Arsip adalah rekaman kegiatan atau peristiwa dalam berbagai bentuk \& media sesuai dengan perkembangan teknologi informasi \& komunikasi yang dibuat \& diterima oleh lembaga negara, pemerintahan daerah, lembaga pendidikan, perusahaan, organisasi politik, organisasi kemasyarakatan, \& perseorangan dalam pelaksanaan kehidupan bermasyarakat, berbangsa, \& bernegara.

Arsiparis adalah seseorang yang memiliki kompetensi di bidang kearsipan yang diperoleh melalui pendidikan formal dan/atau pendidikan dan pelatihan kearsipan serta mempunyai fungsi, tugas, dan tanggung jawab melaksanakan kegiatan kearsipan.

Arsip UGM merupakan unit pelaksana yang bertugas melakukan pembinaan penyelenggarakaan kearsipan di lingkungan UGM. Hal ini disebutkan dalam Undang-Undang No. 43 Tahun 2009, Pasal 8 ayat (4) Pembinaan kearsipan perguruan tinggi dilaksanakan oleh lembaga kearsipan perguruan tinggi terhadap satuan kerja dan civitas akademika di lingkungan perguruan tinggi. Adapun yang dimaksud pembinaan kearsipan menurut Sauki Hadiwardoyo $(2002,87)$ adalah

Tindakan bersifat instruksional yang pada umumnya berisi saran atau rekomendasi-rekomendasi

pelaksanaan prosedur dan kebijakan kearsipan yang berlaku dan dimaksudkan untuk meningkatkan kualitas penyelenggaraan kearsipan pada setiap instansi/organisasi/ perusahaan.
Selanjutnya, untuk mewujudkan penyelenggaraan kearsipan perguruan tinggi yang komprehensif dan terpadu, Arsip UGM perlu membangun dan melaksanakan suatu sistem kearsipan. Sistem kearsipan yang diterapkan dalam suatu lingkungan perguruan tinggi ini diharapkan dapat berfungsi untuk menjamin ketersediaan arsip. Selain itu, sistem kearsipan yang digunakan sebagai acuan dalam penyelenggaraan kearsipan oleh lembaga kearsipan di lingkungan perguruan tinggi harus didukung oleh sumber daya manusia, prasarana dan sarana, serta sumber daya lain sesuai dengan ketentuan peraturan perundangundangan yang berlaku. Undang-Undang No. 43 Tahun 2009 Pasal 27, menyebutkan:

1) Arsip perguruan tinggi adalah lembaga kearsipan perguruan tinggi.

2) Perguruan tinggi negeri wajib membentuk arsip perguruan tinggi.

3) Pembentukan arsip perguruan tinggi dilaksanakan sesuai dengan ketentuan peraturan perundangundangan.

4) Arsip perguruan tinggi sebagaimana dimaksud pada ayat (1) wajib melaksanakan pengelolaan arsip statis yang diterima dari:

a. satuan kerja di lingkungan perguruan tinggi; dan

b. civitas akademika di lingkungan perguruan tinggi.

Selanjutnya dalam Pasal 28 UndangUndang itu menyebutkan: Selain kewajiban sebagaimana dimaksud dalam Pasal 27 ayat (4), arsip perguruan tinggi memiliki tugas melaksanakan:

a. pengelolaan arsip inaktif yang memiliki retensi sekurangkurangnya 10 (sepuluh) tahun yang berasal dari satuan kerja dan civitas akademika di lingkungan perguruan tinggi; dan

b. pembinaan kearsipan di lingkungan 
perguruan tinggi yang bersangkutan.

Dengan demikian, dapat diketahui bahwa lembaga arsip perguruan tinggi selain berkewajiban melaksanakan pengelolaan arsip statis juga berkewajiban mengelola arsip inaktif serta melakukan pembinaan kearsipan di lingkungan perguruan tinggi.

Kemudian Pasal 36, menyebutkan:

1) Lembaga kearsipan menggiatkan sosialisasi kearsipan sebagaimana dimaksud dalam Pasal 7 huruf h dalam mewujudkan masyarakat sadar arsip.

2) Sosialisasi kearsipan sebagaimana dimaksud pada ayat (1) dilakukan melalui pendidikan, pelatihan, bimbingan, dan penyuluhan serta melalui penggunaan berbagai sarana media komunikasi dan informasi.

3) Sosialisasi kearsipan sebagaimana dimaksud pada ayat (1) ditujukan pada lembaga negara, pemerintahan daerah, lembaga pendidikan, perusahaan, organisasi politik, organisasi kemasyarakatan, dan perseorangan.

4) Lembaga kearsipan menyediakan layanan informasi arsip, konsultasi, dan bimbingan bagi pengelolaan arsip masyarakat.

Berdasarkan pasal tersebut dapat diketahui bahwa dalam pembinaan kearsipan perguruan tinggi tercakup juga kegiatan akuisisi, pengolahan arsip statis dan preservasi arsip.

Untuk dapat melaksanakan UndangUndang No. 43 Tahun 2009 perlu memperhatikan Peraturan Pemerintah RI Nomor 28 Tahun 2012 tentang Pelaksanaan Undang-Undang Nomor 43 Tahun 2009 tentang Kearsipan. Dalam Pasal 11 ayat (4), disebutkan:

Lembaga kearsipan perguruan tinggi bertanggung jawab melakukan pembinaan kearsipan terhadap satuan kerja pada rektorat, fakultas, civitas akademika dan/ atau unit kerja dengan sebutan lain di lingkungan perguruan tinggi.

Pembinaan kearsipan di lingkungan perguruan tinggi juga diatur dalam Peraturan Kepala Arsip Nasional Republik Indonesia Nomor 22 Tahun 2012 tentang Desain Pembinaan Kearsipan pada Pemerintahan Daerah. Pasal 4 ayat 3 peraturan tersebut menyebutkan:

Pembinaan Kearsipan terhadap satuan kerja pada rektorat, fakultas, civitas akademika, dan/atau unit kerja dengan sebutan lain di lingkungan perguruan tinggi merupakan tanggung jawab Lembaga Kearsipan Perguruan Tinggi.

Berdasarkan ketiga produk hukum di atas dapat diketahui bahwa ketiganya mengamanatkan perguruan tinggi untuk melaksanakan pembinaan kearsipan. Salah satu kegiatan pembinaan kearsipan yang dilakukan oleh Arsip UGM adalah dengan kegiatan pendampingan dan pengembangan records center di unit kerja di lingkungan UGM. Kegiatan ini dilaksanakan oleh arsiparis Arsip UGM. Arsiparis UGM bertugas mendampingi arsiparis/petugas pengelola arsip di unit kerja agar kegiatan pengelolaan arsip dapat berjalan dengan baik.

\section{HASIL DAN PEMBAHASAN}

Kegiatan pembinaan arsip unit kerja ini telah dilaksanakan sebelum Peraturan Pemerintah Nomor 12 Tahun 2012 keluar. Kegiatan ini telah dilaksanakan oleh Arsip UGM sejak tahun 2009 di bawah kepemimpinan Kepala Arsip UGM Drs. Machmoed Effendhie, M.Hum. Adapun yang dilaksanakan dalam 
kegiatan pembinaan arsip unit kerja adalah sebagai berikut:

1. Melakukan pendampingan dan pengembangan unit kerja yang sudah memiliki Records Center maupun yang akan mendirikan Records Center.

2. Pendampingan prosedur dan tatacara pembentukan Records Center dan desain tata ruang

3. Melakukan pendampingan terhadap kegiatan-kegiatan yang harus dilakukan di Records Center, seperti memilah dan mengidentifikasi arsip, mendiskripsi dan menyusun skema arsip, melakukan manuver dan penataan fisik arsip, menyusun daftar pertelaan arsip (DPA) definitif, melakukan penilaian dan penyusutan arsip, menyusun DPA Serah, menyusun DPA Musnah dan pendampingan dalam menyusun Berita Acara Serah dan Musnah.

Adanya kegiatan ini diharapkan unit kerja mampu menjamin keselamatan bahan pertanggungjawaban nasional tentang perencanaan, pelaksanaan dan penyelenggaraan kehidupan kebangsaan serta untuk menyediakan bahan pertanggungjawaban bagi kegiatan pemerintah, sesuai dengan yang diamanahkan dalam pasal 3 UndangUndang Nomor 43 Tahun 2009. Dalam uraian yang lebih sederhana, setiap unit kerja mampu menjalankan suatu sistem kearsipan yang baik. Sistem kearsipan dikatakan baik, apabila:

1. Mudah dilaksanakan

Sistem kearsipan harus mudah dilaksanakan, sehingga tidak menimbulkan kesulitan, dalam penyimpanan, pengambilan dan pengembalian arsip-arsip.

2. Mudah dimengerti

Sistem kearsipan harus mudah dimengerti sehingga tidak menimbulkan banyak kesalahan dalam pelaksanaannya. Dengan kata lain, sistem kearsipan harus sederhana dan sesuai dengan jenis dan luas lingkup kegiatan organisasi.

3. Murah/ ekonomis

Sistem kearsipan memerlukan dana/ biaya, pemakaian tenaga, dan peralatan/ perlengakapan arsip sesedikit mungkin.

4. Tidak memakan tempat

Tempat penyimpanan arsip tidak terlalu banyak membutuhkan tempat.

5. Mudah dicapai

Sistem kearsipan yang dilaksanakan harus memungkinkan arsip-arsip yang disimpan mudah dan cepat ditemukan, diambil dan dikembalikan, apabla sewaktuwaktu diperlukan lagi.

6. Fleksibel atau luwes

Fleksibel atau luwes berarti sistem filing yang dipergunakan dapat diterapkan di setiap satuan organisasi dan dapat mengikuti perkembangan organisasi. Sumber: https://www.anugerahdino.com)

Akan tetapi, dalam pelaksanaannya belum semua unit kerja menjalankan suatu sistem kearsipan dengan baik sejak dari penciptaan sampai dengan penyusutan. Kebanyakan unit kerja sudah baik pada waktu pengelolaan arsip dinamis aktif, namun saat menjadi inaktif tidak dilakukan pemindahan sesuai dengan prosedur kearsipan sehingga saat inaktif dibiarkan begitu saja tanpa ada penataan sesuai dengan pola/system pada saat dinamis, atau menggunakan system tertentu, tanpa ada penyusutan, dan tanpa ada pemeliharaan. Hal itu mengakibatkan penumpukan arsip, menimbulkan kesulitan saat akan mengakses suatu arsip dan mempercepat kerusakan arsip.

Apabila unit kerja sudah terbentur dengan masalah tersebut biasanya baru timbul keinginan dari unit kerja untuk membenahi pengelolaan arsipnya. Salah satu langkah yang ditempuh oleh unit 
kerja yang mengalami masalah tersebut biasanya dengan berkoordinasi dengan Arsip UGM untuk dilakukan pembinaan dan pendampingan arsip unit kerja untuk membenahi permasalahan kearsipan yang ada. Selanjutnya Pimpinan Arsip akan menugaskah arsiparis untuk melaksanakan tugas pembinaan arsip unit kerja. Para arsiparis Arsip UGM yang bertugas melaksanakan kegiatan pembinaan arsip unit kerja harus mampu bekerja keras dan bekerja sama dengan arsiparis/ pengelola arsip di unit kerja.

Pelaksanaan kegiatan pendampingan arsip unit kerja ini dilaksanakan berdasarkan permintaan dari unit kerja dan unit kerja yang menjadi target dari Arsip UGM. Yang dimaksud dengan permintaan dari unit kerja adalah suatu unit kerja mengajukan permohonan pendampingan arsip ke Arsip UGM. Biasanya unit kerja yang minta pembinaan adalah unit kerja yang mengalami kendala dalam penataan arsip dan bingung ketika akan menyusutkan arsip. Sedangkan yang dimaksud dengan unit kerja yang menjadi target dari Arsip UGM adalah unit kerja yang karena tupoksinya banyak menghasilkan arsiparsip yang berkategori permanen sehingga unit kerja tersebut menjadi prioritas pendampingan agar arsip-arsip yang berkategori permanen tersebut bisa diselamatkan dan bisa diserahkan ke Arsip UGM atau diakuisisi oleh Arsip UGM.

Berikut adalah uraian tentang pendampingan arsip yang telah dilaksanakan oleh Arsip UGM dalam beberapa tahun terakhir (tahun 20142018):

\section{Tahun 2014}

Secara normatif pengelolaan arsip dilakukan secara berjenjang dan melibatkan banyak pihak. Pengelolaan tersebut tidak akan baik jika hanya dilaksanakan oleh Arsip UGM, tanpa dukungan dan kerjasama dari unit-unit kerja (fakultas, pusat studi, lembaga, direktorat, bagian dll.). Pembinaan unit kerja ini dimaksudkan untuk mendampingi dan menggalang kerjasama sekaligus media pembinaan kepada unit kerja. Sepanjang 2014 kegiatan pendampingan dilakukan kepada tiga fakultas, yaitu:

1. Fakultas Hukum,

2. Fakultas MIPA, dan

3. Fakultas Isipol.

Selain tiga fakutas tersebut, telah dirintis pula pendampingan yang baru sampai pada tahap survei pada Bagian Hukum dan Organisasi UGM dan Jurusan Elektro Fakultas Teknik.

\section{Tahun 2015}

Pembinaan arsip unit kerja dilakukan untuk mendampingi dan memantau sekaligus memberikan solusi dalam masalah pengelolaan arsip unit kerja di lingkungan UGM. Kegiatan pembinaan ini dilakukan secara berkesinambungan. Kegiatan pembinaan arsip unit kerja yang dilakukan pada tahun 2015 merupakan kegiatan lanjutan tahun 2014 dan pembinaan unit kerja lain yang baru dilakukan pada tahun 2015.

Selain pembinaan arsip unit kerja, Arsip UGM juga memberikan "Penghargaan Kearsipan kepada Unit Kerja". Pemberian penghargaan ini diberikan dalam rangka menyemarakkan Dies Arsip UGM ke-11. Arsip UGM memberikan penghargaan kepada unit kerja di lingkungan UGM yang telah melaksanakan pengelolaan arsip dengan baik. Penghargaan tersebut diberikan kepada:

1. Records Center Direktorat Sumber Daya Manusia sebagai Records Center Terbaik di lingkungan Kantor Pusat UGM

2. Records Center Fakultas Psikologi sebagai Records Center Terbaik Tingkat Fakultas di lingkungan UGM 
Tabel 1. Pembinaan Arsip Unit Kerja UGM Tahun 2015

\begin{tabular}{|c|c|c|c|c|}
\hline No. & Unit Kerja & Tanggal & $\begin{array}{c}\text { Sasaran Pendamp- } \\
\text { ingan }\end{array}$ & Keterangan \\
\hline 1 & $\begin{array}{l}\text { Direktorat Akad- } \\
\text { emik (Direktorat } \\
\text { Pendidikan dan } \\
\text { Pengajaran) }\end{array}$ & $\begin{array}{l}\text { Jan - } \\
\text { April } \\
2015\end{array}$ & $\begin{array}{l}\text { Scan data registrasi } \\
\text { mahasiswa tahun } \\
2004-2013 \text { dan } \\
2014,2015 \\
\text { (digitalisasi arsip) }\end{array}$ & $\begin{array}{ll}- & \text { kelanjutan tahun } \\
2014 \\
-\quad 4 \text { mahasiswa magang } \\
\text { selama } 2 \text { bulan } \\
\text { - } \quad \text { selesai tanggal } 15 \\
\text { April 2015 }\end{array}$ \\
\hline 2 & Fakultas Hukum & 2014 & Arsip inaktif & $\begin{array}{ll}- & \text { kelanjutan tahun } \\
2014 \\
\text { - } \\
\text { melibatkan } 4 \text { alumni } \\
\text { D3 Arsip }\end{array}$ \\
\hline 3 & Fakultas Isipol & 2014 & $\begin{array}{l}\text { Arsip inaktif } \\
\text { (records center) }\end{array}$ & $\begin{array}{ll}- & \text { kelanjutan tahun } \\
& 2014 \\
- & \text { melibatkan } 2 \text { alumni }\end{array}$ \\
\hline 4 & $\begin{array}{l}\text { Pusat Pengadaan } \\
\text { dan Logistik }\end{array}$ & Jan 2015 & $\begin{array}{l}\text { Pengelolaan dan pe- } \\
\text { nataan arsip dinamis } \\
\text { (aktif dan inaktif) }\end{array}$ & \\
\hline 5 & $\begin{array}{l}\text { Kantor Jaminan } \\
\text { Mutu }\end{array}$ & $\begin{array}{l}\text { Feb } \\
2015\end{array}$ & $\begin{array}{l}\text { Pengelolaan dan pe- } \\
\text { nataan arsip dinamis } \\
\text { (aktif dan inaktif) }\end{array}$ & \\
\hline 6 & $\begin{array}{l}\text { Fakultas Kedok- } \\
\text { teran }\end{array}$ & $\begin{array}{l}\text { Feb } \\
2015\end{array}$ & $\begin{array}{l}\text { Penataan arsip aktif } \\
\text { prodi pendidikan } \\
\text { dokter ( } 7 \text { divisi) }\end{array}$ & $\begin{array}{l}\text { Dikerjakan oleh } \\
4 \text { alumni D3 Arsip } \\
\text { Sekolah vokasi }\end{array}$ \\
\hline 7 & $\begin{array}{l}\text { Fakultas } \\
\text { Ekonomika dan } \\
\text { Bisnis }\end{array}$ & $\begin{array}{l}\text { Feb } \\
2015\end{array}$ & $\begin{array}{l}\text { Penilaian dan } \\
\text { penyusutan arsip } \\
\text { (arsip dinamis aktif } \\
\text { (surat masuk dan } \\
\text { keluar) serta pemisa- } \\
\text { han antara central } \\
\text { file dengan records } \\
\text { center }\end{array}$ & $\begin{array}{l}\text { Dikerjakan } 2 \text { alumni D3 } \\
\text { Arsip Sekolah Vokasi }\end{array}$ \\
\hline 8 & $\begin{array}{l}\text { Direktorat Keu- } \\
\text { angan }\end{array}$ & $\begin{array}{l}\text { Sept } \\
2015\end{array}$ & $\begin{array}{l}\text { Penataan, penilaian } \\
\text { dan penyusutan arsip }\end{array}$ & $\begin{array}{ll}\text { - } & \text { Pengelolaan arsip } \\
\text { inaktif Direktorat } \\
\text { Keuangan } \\
\text { - Dikerjakan oleh } 2 \\
\text { alumni D3 Arsip } \\
\text { Sekolah Vokasi }\end{array}$ \\
\hline 9 & $\begin{array}{l}\text { Fakultas Psikolo- } \\
\text { gi }\end{array}$ & $\begin{array}{l}\text { Sept } \\
2015\end{array}$ & $\begin{array}{l}\text { Pengelolaan arsip } \\
\text { aktif arsip keuangan }\end{array}$ & $\begin{array}{l}\text { Dikerjakan oleh } 2 \text { alumni } \\
\text { D3 Arsip Sekolah Vokasi }\end{array}$ \\
\hline
\end{tabular}

Sumber: Arsip UGM

3. Direktorat Keuangan sebagai Unit

atas 10 tahun.

Kerja yang paling aktif

memindahkan arsip beretensi di 
Penghargaan yang diberikan kepada unit kerja yang berprestasi adalah berupa sertifikat dan 100 buah boks arsip.

Selain pembinaan ke unit kerjanya, pembinaan kearsipan juga dilaksanakan terhadap SDM Kearsipan di Lingkungan UGM. Pembinaan SDM kearsipan ini dilakukan terhadap 18 arsiparis PNS, 4 arsiparis PTN BH, dan 36 pengelola arsip/ petugas kearsipan. SDM kearsipan tersebut tersebar di berbagai unit kerja di lingkungan UGM. Pembinaan dilakukan untuk meningkatkan kompetensi SDM kearsipan yang ada supaya mereka dapat melaksanakan kegiatan kearsipan dengan baik di unit kerja masing-masing. Kegiatan pembinaan yang telah dilakukan selama tahun 2015 dapat dilihat dalam tabel berikut. melaksanakan kegiatan pendampingan arsip unit kerja dalam rangka

Tabel 3 Pembinaan Arsip Unit Kerja Tahun 2016

\begin{tabular}{|c|c|c|}
\hline$\overline{\mathbf{N}}$ & Nama Unit Kerja & Keterangan \\
\hline 1 & $\begin{array}{ll}\text { Direktorat } & \text { Keu- } \\
\text { angan } & \end{array}$ & $\begin{array}{l}\text { melanjutkan } \\
\text { tahun } 2015\end{array}$ \\
\hline 2 & Fakultas ISIPOL & $\begin{array}{l}\text { melanjutkan } \\
\text { tahun } 2015\end{array}$ \\
\hline 3 & $\begin{array}{ll}\text { Fakultas } & \text { MIPA } \\
\text { UGM } & \\
\end{array}$ & $\begin{array}{l}\text { melanjutkan } \\
\text { tahun } 2015\end{array}$ \\
\hline 4 & Fakultas Pertanian & \\
\hline 6 & Fakultas Teknik & \\
\hline 7 & $\begin{array}{l}\text { Fakultas Ekonomika } \\
\text { dan Bisnis }\end{array}$ & \\
\hline 8 & Resimen Mahasiswa & \\
\hline 9 & Fakultas Kedokteran & \\
\hline $\begin{array}{l}1 \\
0\end{array}$ & $\begin{array}{lll}\begin{array}{l}\text { Fakultas Ilmu } \\
\text { daya }\end{array} & & \\
\end{array}$ & \\
\hline $\begin{array}{l}1 \\
1\end{array}$ & Direktorat SDM & \\
\hline $\begin{array}{l}1 \\
2 \\
\end{array}$ & $\begin{array}{l}\text { Direktorat } \\
\text { Perencanaan }\end{array}$ & \\
\hline
\end{tabular}

Tabel 2 Kegiatan Pembinaan SDM Kearsipan UGM Tahun 2015

\begin{tabular}{|c|l|l|l|l|}
\hline $\begin{array}{c}\text { No } \\
\cdot\end{array}$ & \multicolumn{1}{|c|}{ Kegiatan } & \multicolumn{1}{|c|}{ Tanggal } & Tempat & \multicolumn{1}{c|}{ Tema } \\
\hline 1 & $\begin{array}{l}\text { Diskusi Kearsipan } \\
\text { dan Workshop }\end{array}$ & $\begin{array}{l}28 \text { April } \\
2015\end{array}$ & Arsip UGM & $\begin{array}{l}\text { Draf Pedoman Penyusutan } \\
\text { Arsip di Lingkungan } \\
\text { UGM }\end{array}$ \\
\hline 2 & $\begin{array}{l}\text { Diskusi Kearsipan } \\
\text { Kerjasama dengan } \\
\text { Forsipagama }\end{array}$ & 26 Mei 2015 & Arsip UGM & $\begin{array}{l}\text { Sosialisasi Permen PAN } \\
\text { RB No. 48 Tahun 2014 } \\
\text { tentang Jabatan Fungsion- } \\
\text { al Arsiparis }\end{array}$ \\
\hline 3 & $\begin{array}{l}\text { Studi Banding ke PT } \\
\text { KAI dan BPAD Jawa } \\
\text { Barat }\end{array}$ & $\begin{array}{l}5-6 \text { Juni } \\
2015\end{array}$ & $\begin{array}{l}\text { PT KAI dan } \\
\text { BPAD Ja- } \\
\text { wa Barat }\end{array}$ & Manajemen Kearsipan \\
\hline 4 & Pembinaan SDM & 29 Juli 2015 & Arsip UGM & \begin{tabular}{l} 
Pembinaan Motivasi SDM \\
\hline 5
\end{tabular} \\
$\begin{array}{l}\text { Diskusi Kearsipan } \\
\text { Kerjasama dengan } \\
\text { Forsipagama }\end{array}$ & 24 November & $\begin{array}{l}\text { Fakultas } \\
\text { Ekonomika } \\
\text { dan Bisnis } \\
\text { UGM }\end{array}$ & $\begin{array}{l}\text { Pengelolaan Arsip Inaktif } \\
\text { "Sistem Informasi Mana- } \\
\text { jemen Arsip Inaktif } \\
\text { (SIKI)" }\end{array}$ \\
\hline
\end{tabular}

Tahun 2016

Pembinaan Arsip Unit Kerja yang dilaksanakan oleh Arsip UGM pada tahun 2016 ini meningkat jika dibandingkan dengan tahun sebelumnya. Arsip UGM mewujudkan pengelolaan arsip yang lebih di 11 unit kerja, lihat table 3.

Dengan meningkatnya kesadaran pengelolaan arsip oleh unit kerja di lingkungan UGM, berpengaruh pula 
dengan meningkatnya jumlah unit kerja yang didampingi oleh Arsip UGM melalui kegiatan pembinaan arsip unit kerja pada tahun 2017. Berikut ini adalah tabel pembinaan arsip unit kerja yang dilaksanakan oleh Arsip UGM pada tahun 2017:

\section{Output Pembinaan Arsip Unit Kerja}

Output yang diperoleh dari kegiatan pembinaan arsip unit kerja adalah terkelolanya arsip sehingga mudah dan cepat ditemukan apabila akan digunakan sewaktu-waktu. Dengan demikian dapat dikatakan bahwa dengan kegiatan

Tabel 4 Pembinaan Arsip Unit Kerja Tahun 2017

\begin{tabular}{|c|l|l|l|}
\hline $\begin{array}{c}\text { No } \\
\cdot\end{array}$ & \multicolumn{1}{|c|}{ Unit Kerja } & \multicolumn{1}{c|}{ Jenis Arsip } & \multicolumn{1}{c|}{ Keterangan } \\
\hline 1 & Fakultas ISIPOL & & Lanjutan \\
\hline 2 & Fakultas MIPA UGM & & Lanjutan \\
\hline 3 & $\begin{array}{l}\text { Fakultas Ekonomika dan } \\
\text { Bisnis }\end{array}$ & & Lanjutan \\
\hline 4 & Fakultas Farmasi & Tekstual & Lanjutan \\
\hline 5 & Dit. Perencanaan & $\begin{array}{l}\text { Tekstual; Kearsitekturan \& } \\
\text { Kartografi }\end{array}$ & \\
\hline 6 & Fakultas Teknik & Tekstual & \\
\hline 7 & Dit. Penelitian & Tekstual & \\
\hline 8 & HUKOR & Tekstual & \\
\hline 9 & Senat Akademik & Tekstual & \\
\hline 10 & MWA & Tekstual & \\
\hline 11 & PSBA & Tekstual, Foto & \\
\hline 12 & $\begin{array}{l}\text { Badan Publikasi dan Pen- } \\
\text { erbitan (BPP) UGM }\end{array}$ & Tekstual & \\
\hline 13 & $\begin{array}{l}\text { Direktorat Pendidikan dan } \\
\text { Pengajaran }\end{array}$ & Tekstual; Arsip Elektronik & \\
\hline
\end{tabular}

Berikut ini adalah tabel pembinaan arsip unit kerja yang dilaksanakan oleh Arsip UGM pada tahun 2018: pembinaan arsip unit kerja dapat menyelamatkan arsip unit kerja yang merupakan aset bagi universitas. Selain itu dengan kegiatan pembinaan arsip unit

Tabel 5 Pembinaan Arsip Unit Kerja Tahun 2018

\begin{tabular}{|c|l|l|l|}
\hline $\begin{array}{c}\text { No } \\
\cdot\end{array}$ & \multicolumn{1}{|c|}{ Unit Kerja } & \multicolumn{1}{c|}{ Jenis Arsip } & \multicolumn{1}{c|}{ Keterangan } \\
\hline 1 & Fakultas ISIPOL & & Lanjutan \\
\hline 2 & Fakultas MIPA UGM & & Lanjutan \\
\hline 3 & $\begin{array}{l}\text { Fakultas Ekonomika dan } \\
\text { Bisnis }\end{array}$ & & Lanjutan \\
\hline 4 & Fakultas Farmasi & Tekstual & Lanjutan \\
\hline 5 & Fakultas Filsafat & Tekstual & \\
\hline 6 & Dit. Aset & $\begin{array}{l}\text { Tekstual; Gambar Teknik } \\
\text { dan Kearsitekturan; Arsip } \\
\text { Foto }\end{array}$ & \\
\hline 7 & PSBA & Tekstual, Foto & \\
\hline 8 & BPPM Balairung UGM & & \\
\hline
\end{tabular}


kerja mendatangkan manfaat lain yaitu pendirian records center unit kerja dan penyerahan arsip statis oleh unit kerja ke Arsip UGM. Berdasarkan pengalaman yang diperoleh oleh penulis pada saat melaksanakan kegiatan pembinaan arsip unit kerja, banyak unit kerja yang memandang bahwa arsip itu penting dan perlu ruang simpan khusus dengan peralatan simpan arsip sesuai dengan kaidah kearsipan. Berikut adalah tabel unit kerja yang mendirikan records center:

Tabel 6 Records Center yang Terbentuk dari Kegiatan Pendampingan Arsip

\begin{tabular}{|c|l|}
\hline No & \multicolumn{1}{|c|}{ Nama Unit Kerja } \\
\hline 1 & Fakultas Biologi \\
\hline 2 & Fakultas Geografi \\
\hline 3 & Fakultas Kedokteran Gigi \\
\hline 4 & Fakultas ISIPOL \\
\hline 5 & Fakultas Hukum \\
\hline 6 & Fakultas Psikologi \\
\hline 7 & Dit. Perencanaan \\
\hline 8 & Dit. Penelitian \\
\hline 9 & Dit. Aset \\
\hline
\end{tabular}

Berikut adalah penyerahan arsip statis yang dilakukan oleh unit kerja kepada Arsip UGM:

\section{Kendala}

Dalam melaksanakan tugas pembinaan arsip unit kerja tidaklah semudah membalikkan telapak tangan. Banyak kendala yang dihadapi di lapangan. Kendala-kendala yang dihadapi pada kegiatan pembinaan arsip unit kerja, antara lain:

1. Kurangnya kesadaran akan arti penting arsip

Kendala terbesar yang dihadapi dalam pembinaan arsip unit kerja adalah belum adanya kesadaran akan arti penting arsip. Dengan belum adanya kesadaran ini akan berdampak arsip tidak akan dikelola dengan baik karena arsip akan dibiarkan teronggok di gudang, disimpan tanpa ada sarana temu baliknya dan tanpa ada pemeliharaan arsip. Hal ini bisa menimbulkan kerusakan pada fisik arsip yang berakibat pula pada hilangnya suatu informasi. Selain itu, banyak pandangan yang mengganggap bidang kearsipan tidak penting sehingga menghambat perkembangan bidang kearsipan.

2. Kurangnya Sumber Daya Manusia (SDM)

Kendala dari sisi SDM adalah berkaitan dengan kuantitas dan kualitas. Jumlah SDM bidang

Tabel 7 Penyerahan Arsip Statis Karena Kegiatan Pembinaan Arsip Unit Kerja

\begin{tabular}{|c|l|l|l|}
\hline No. & \multicolumn{1}{|c|}{ Unit Kerja } & \multicolumn{1}{c|}{ Tahun } & \multicolumn{1}{c|}{ Jenis Arsip } \\
\hline 1. & $\begin{array}{l}\text { Dit. Perencanaan dan Pengem- } \\
\text { bangan (Renbang) }\end{array}$ & 2009 & $\begin{array}{l}\text { Tekstual; Gambar Teknik dan } \\
\text { Kearsitekturan }\end{array}$ \\
\hline 2. & Senat Akademik & $2013 ; 2017$ & Tekstual \\
\hline 3. & Fakultas Kedokteran & 2016 & Tekstual \\
\hline 4. & Resimen Mahasiswa & 2016 & Tekstual \\
\hline 5. & PSBA & 2017 & Foto \\
\hline 6. & Dit. Perencanaan & 2017 & $\begin{array}{l}\text { Tekstual; Gambar Teknik dan } \\
\text { Kearsitekturan }\end{array}$ \\
\hline
\end{tabular}

kearsipan belum memenuhi

kebutuhan sehingga arsip yang 
tercipta tidak sebanding dengan jumlah SDM yang ada. Bahkan banyak unit kerja yang tidak memberikan plot khusus pegawai sebagai petugas arsip. Biasanya pekerjaan arsip hanya menjadi tugas tambahan bagi salah seorang pegawai. Terkait dengan masalah kualitas, biasanya pegawai yang ditempatkan di bagian arsip bukan berlatar belakang pendidikan kearsipan. Akibatnya pekerjaan kearsipan lebih sering tidak tersentuh oleh pegawai tersebut. Bahkan ada unit kerja yang mempunyai arsiparis tetapi arsiparis tersebut tidak diberi pekerjaan kearsipan. Apabila unit kerja yang mengajukan pembinaan tidak mempunyai arsiparis atau pegawai khusus untuk mengelola arsip, Arsip UGM biasanya menyarankan untuk merekrut tenaga kontrak dari alumsi D3 Kearsipan UGM atau tenaga paruh waktu dari mahasiswa D3 Kearsipan. Tenaga kontrak atau tenaga paruh waktu tersebut yang bekerja untuk mengolah dan mengelola arsip di unit kerja tersebut dengan bimbingan dari arsiparis yang ditugaskan untuk melaksanakan pembinaan arsip unit kerja.

3. Kurangnya sarana dan prasarana.

Keterbatasan sarana dan prasarana kearsipan yang sesuai dengan standard juga menimbulkan kesulitan tersendiri dalam pengelolaan arsip. Keterbatasan sarana dan prasarana kearsipan yang belum sesuai dengan standard biasanya terkait dengan masalah anggaran untuk bidang kearsipan yang masih minim. Hal ini juga diakibatkan karena bidang kearsipan belum dianggap penting maka alokasi anggaran untuk bidang kearsipan pun belum "dipikirkan", belum "dialokasikan" atau kalaupun sudah dianggarkan masih sangat kecil. Hal ini mengakibatkan banyak unit kerja yang belum mempunyai records center.

4. Sistem

Sistem disini bisa berarti beberapa hal yaitu sistem kearsipan secara manual, sistem kearsipan secara elektronik dan sistem dalam pembagian tugas kearsipan antara unit pengolah dan unit kearsipan. Banyaknya sistem kearsipan yang digunakan oleh unit kerja di lingkungan UGM yang sangat beragam juga menimbulkan masalah tersendiri. Hal ini berkaitan dengan sarana simpan yang berbeda, cara penyimpanan yang berbeda dan dalam pengembangan sistem elektronik kearsipan juga berbeda-beda. Oleh karena itu, sejak tahun 2015 Arsip UGM melakukan survei kearsipan di beberapa unit kerja yang meliputi seluruh fakultas, seluruh direktorat, beberapa pusat studi, perpustakaan, laboratorium dan badan usaha di lingkungan UGM dalam rangka menyusun Norma Standar Prosedur dan Kriteria Kearsipan (NSPK) bidang arsip dinamis, yaitu pola klasifikasi arsip, jadwal retensi arsip dan sistem klasifikasi keamanan dan akses arsip. Pada tahun 2018 ini, semua draf sudah berada dalam tahan finishing di Hukum dan Organisasi (Hukor) UGM menunggu persetujuan Rektor UGM. NSPK ini yang akan digunakan dalam menyempurnakan sistem kearsipan elektroniknya.

\section{Cara Mengatasi Masalah}

Adapun cara mengatasi permasalahan tersebut yang bisa dilakukan melalui kegiatan pembinaan arsip unit kerja, antara lain: 
1. Sumber Daya Manusia (SDM) Memberikan motivasi dan menyamakan persepsi bahwa bidang kearsipan merupakan bidang yang penting kepada arsiparis/ pengelola arsip agar kinerja arsiparis dan pengelola arsip bisa meningkat dan lebih baik. Apabila arsip terkelola dengan baik akan mudah ditemukan jika suatu waktu diperlukan sehingga dapat meningkatkan kinerja unit kerja.

2. Sarana dan Prasarana

Dalam kegiatan pembinaan arsip unit kerja, Arsip UGM biasanya memberikan bantuan boks arsip dalam jumlah tertentu kepada unit kerja tersebut untuk mengenalkan dan memberi contoh sarana penyimpanan arsip inaktif ke dalam boks arsip (terutama bagi unit kerja/ records center yang belum mempunyai boks arsip). Selain itu, dalam kegiatan pendampingan ini juga memberikan masukan-masukan agar memanfaatkan sarana dan prasarana yang ada secara optimal.

3. Sistem

Dalam rangka mengatasi permasalahan terkait sistem, penulis menyarankan pembenahan sistem kearsipan agar sesuai dengan ketentuan yang berlaku dan sesuai dengan kondisi unit kerja, antara lain dengan menggunakan klasifikasi arsip untuk memberkaskan arsip sehingga tidak ada lagi pemisahan antara surat masuk dan surat keluar. Dengan kata lain surat masuk dan surat keluar memberkas menjadi satu kesatuan sesuai dengan subjeknya masing-masing. Selain itu penulis juga memberikan masukan agar ada pembagian tugas yang jelas antara records center/ unit kearsipan dengan unit pengolah dengan penunjukan petugas sebagai penanggung jawab masing masing unit tersebut. Untuk sistem pengarsipan berdasarkan elektronik khususnya untuk arsip inaktif, Arsip
UGM bekerjasama dengan

Direktorat Sistem dan Sumber Daya Informasi (DSSDI) UGM membuat Sistem Kearsipan Inaktif (SIKI) yang dapat digunakan oleh semua unit kerja di lingkungan UGM.

\section{KESIMPULAN}

Kegiatan pembinaan arsip unit kerja meliputi pembinaan kepada unit kerja dan pembinaan kepada SDM kearsipan. Kegiatan ini merupakan kegiatan pembinaan kearsipan di lingkungan UGM untuk melaksanakan amanah UndangUndang Nomor 43 Tahun 2009. Adanya kegiatan ini diharapkan dapat meningkatkan pengelolaan arsip unit kerja di lingkungan UGM, sehingga arsip dapat terkelola dengan baik dan dapat menyelamatkan memori kolektif bangsa bagi generasi sekarang dan yang akan datang. Akan tetapi, dalam pelaksanaannya kegiatan pembinaan unit kerja ini masih menghadapi berbagai kendala dan hambatan. Melalui kegiatan pembinaan arsip unit kerja ini, penulis berharap SDM kearsipan khususnya arsiparis dan pengelola arsip di unit kerja turut aktif pada saat kegiatan pembinaan arsip unit kerja berlangsung sehingga pengelolaan arsip di unit kerja dapat berkesinambungan dengan baik di masa yang akan datang. Hal ini sangat penting karena pengelolaan arsip yang baik di suatu perguruan tinggi sangat penting karena perguruan tinggi merupakan salah satu aset yang sangat berharga bagi Negara Indonesia.

\section{DAFTAR PUSTAKA}

Sauki Hadiwardoyo, 2002, Terminologi Kearsipan Nasional, Arsip Nasional Republik Indonesia, Jakarta.

V. Wiratna Sujarwadi, 2014, Metodologi Penelitian, Pustaka Baru Press, Yogyakarta.

Undang-Undang Dasar Republik Indonesia 1945. 
Undang-Undang No. 14 Tahun 2008 "Masih Banyak Instansi yang Belum Tahu tentang Keterbukaan Informasi Publik.

Peranan Arsip" http:// www.suaramerdeka.com/

Undang-Undang No. 43 Tahun 2009 tentang Kearsipan. harian/0507/18/pan02.htm, 5 Juni 2013.

Peraturan Pemerintah RI Nomor 28 Tahun 2012 tentang Pelaksanaan UndangUndang Nomor 43 Tahun 2009 tentang Kearsipan.

Peraturan Kepala Arsip Nasional RI No. 8 Tahun 2009 tentang Program Arsip Masuk Desa.

Peraturan Kepala Arsip Nasional RI No. 7 Tahun 2017 tentang Gerakan Nasional Sadar Tertib Arsip.

\section{Internet}

Tugas dan Fungsi ANRI, Sumber: http:// www.anri.go.id/detail/39-102-

Tugas-Pokok-Fungsi, diakses 6 Maret 2018.

Visi dan Misi Arsip UGM, Sumber: http:// arsip.ugm.ac.id/profile/visi-misi, diakses 8 Maret 2018.

https://twitter.com/arsipnasionalri/ status/844791356371349506, diakses 27 September 2018.

"Presiden Canangkan Arsip Masuk Desa", http:// edukasi.kompas.com/read/2009/ $\underline{08 / 31 /}$ $14105690 /$

Presiden.Canangkan.Arsip.Masuk.D esa, diakses 27 September 2018.

Pembinaan Kearsipan Pemerintah Provinsi Daerah Istimewa Yogyakarta oleh Anna Nunuk Nuryani, Dra. http:// www.bpadjogja.info/file/ 4e8b8622b11650380def737f68fed ee1. pdf, diakses 5 Juni 2013.

"Pemilihan Sistem Penyimpanan Arsip Yang Sesuai",

https://

www.anugerahdino.com/2014/01/ pemilihan-sistem-penyimpananarsip-yang.html, diakses 28 September 2018. 